\title{
A prospective view of the impact of prime validity on response speed and selection in the arrow classification task with free choice trials
}

\author{
JASOn R. Perry ANd Stephen J. Lupker \\ University of Western Ontario, London, Ontario, Canada
}

\begin{abstract}
Bodner and Masson $(2001,2003,2004)$ demonstrated that masked priming effects in many cognitive tasks become larger when the proportion of related trials increases (prime validity effects). Those authors claimed that these effects are due to participants' recruiting prime information to aid target processing when it is useful to do so (e.g., there are a large number of related trials - the memory recruitment account). Bodner and Mulji (in press) recently reported similar effects in an arrow classification task with free choice trials. In the present research, we examined whether the memory recruitment account can adequately explain prime validity effects in that task. In this experiment, participants classified arrow direction (i.e., left-right) and responded to free choice stimuli (i.e., two-sided arrows that allow either a left or right response) following arrow primes when the prime-target relationship for the arrow target trials was always congruent, always incongruent, or unpredictive. Prime validity effects for the either-way targets emerged with both 77 - and $165-\mathrm{msec}$ prime-target intervals. The results in the unpredictive conditions, however, suggest that those effects were due to the impact of automatic response biases initially created by the prime, which participants attempt to suppress when it is advantageous to do so.
\end{abstract}

In the masked priming paradigm, a forward mask (typically a character string) may or may not be presented prior to a briefly presented (typically 60 -msec or less) prime stimulus, which is then masked by a backward mask and/ or a target stimulus. The goal of this paradigm is to measure the effect of these masked primes on target processing in order to better understand the mechanisms underlying the processing of subliminal stimuli.

In general, there are two views concerning how the presentation of the masked prime affects target processing (see Masson \& Bodner, 2003). The prospective view is based on two assumptions. One assumption is that the presentation of a masked prime induces a temporary state of activation in the cognitive system, which, in turn, affects the speed with which a subsequently presented target is processed. The second assumption is that, since participants do not report any awareness of these masked primes, any episodic trace left by these primes should be so weak that any effect of the prime must have been due solely to automatic, rather than strategic, processes (see also Forster \& Davis, 1984).

The alternative - the retrospective view of masked priming - is based on the idea that both of the assumptions of the prospective view are incorrect, adopting instead two markedly different assumptions. The first is that the primes (even when they are presented briefly and masked) form reasonably strong episodic traces. The second assumption is that, in an effort to aid target processing, the cognitive system strategically adjusts the extent to which it relies on information from these episodic traces (even though the viewer is typically unaware of either the presence of the prime or its identity).

The strongest piece of evidence that masked primes do activate episodic traces that could then be used strategically are prime validity effects - that is, larger priming effects when the percentage of trials in which the target is related to the prime is high (typically $80 \%$ ) relative to when it is low (typically $20 \%$ ). These effects have been found in reaction time latencies across a variety of cognitive tasks (e.g., Bodner \& Dypvik, 2005; Bodner \& Masson, 2001, 2003, 2004; Bodner, Masson, \& Richard, 2006; Bodner \& Mulji, in press; Jaśkowski, Skalska, \& Verleger, 2003; Klapp, 2007). To account for these results, Bodner and Masson (2001; Masson \& Bodner, 2003) proposed their memory recruitment account, which is based on the two core assumptions of the retrospective view of masked priming, to explain how the proportion of congruent prime-target trials affects the size of priming effects.

According to the memory recruitment account, "the processing applied to masked primes is encoded in memory and is then recruited to assist with target processing if the list context ... supports its recruitment" (Bodner \& Mulji, in press). That is, when the information that can be derived from a masked prime is often beneficial for target processing (e.g., a prime arrow often points in the same direction as the target arrow), then the cognitive system adopts a target processing strategy that involves placing some reliance on information derived from the prime's episodic trace. Be-

J. R. Perry, jperry23@uwo.ca 
cause this information benefits target processing on related trials, a greater reliance on prime information produces a larger priming effect. In contrast, as Masson and Bodner (2003) argued, a prospective view of masked priming appears to be unable to explain prime validity effects. If priming were merely due to a temporary change in activation within the cognitive system, that change - and, hence, the size of the priming effect- should not be affected by the proportion of congruent prime-target pairs.

Much of the previous research on the prime validity effect has been done using paradigms in which several different stimuli are used as primes and targets so that each stimulus is seen and classified only once (e.g., lexical decision, naming). In the present research, we investigated these issues in a slightly different situation, one in which only a small set of stimuli was used repeatedly, with those same stimuli also acting as masked primes. In these types of situations, the influence of the masked prime on target classification is presumed to be due to specific stimulus-response associations, which are formed as a result of classifying a small set of visible stimuli (see Damian, 2001). Specifically, the present experiment was designed to investigate the mechanisms that drive the prime validity effect when the task is a target arrow classification task (see also Bodner \& Mulji, in press; Klapp, 2007).

\section{Arrow Classification Tasks (With and Without Free Choice Trials)}

Eimer and Schlaghecken (1998) provided one of the earliest demonstrations of a masked priming effect in an arrow classification task in which arrow targets that require a directional (i.e., left $[<<]$ or right $[>>]$ ) response were preceded by masked prime arrows. Their results were counterintuitive, in that participants responded significantly faster when the prime and target arrows pointed in opposite directions than when they pointed in the same direction (a negative priming effect). Measurements of event-related potentials helped explain this negative priming effect by demonstrating that a masked arrow prime initially activates the motor response that corresponds to the direction of that prime. That is, a response priming effect emerged because of the fact that repeated classifications of left- and rightpointing target arrows strengthened the association between these stimuli and the left and right key responses, associations that are activated by the masked primes. However, as time passes and this response activation diminishes, the opposite motor response becomes activated.

The facilitation-followed-by-inhibition pattern from Eimer and Schlaghecken's (1998) event-related potential measurements suggests that, in an arrow classification task, responses should be faster when prime and target arrows point in the same direction than when they point in opposite directions (positive priming) when the prime-target interval is short, whereas negative priming effects should be obtained when the prime-target interval is long. This response priming pattern has, in fact, been demonstrated in subsequent research (e.g., Eimer, 1999; Eimer \& Schlaghecken, 2002; Schlaghecken \& Eimer, 2000, 2002).

Further research has shown that, in addition to motor response latencies, masked arrow primes also affect re- sponse selection in tasks in which arrow target trials are interspersed with a set of either-way targets $(<>)$ for which either response is legitimate (see Klapp \& Haas, 2005; Klapp \& Hinkley, 2002, Experiment 5; Schlaghecken \& Eimer, 2004; Schlaghecken, Klapp, \& Maylor, 2009, Experiment 2). Specifically, responses in these free choice trials are more frequent and faster when they match the direction of the masked prime at short prime-target intervals, but at longer prime-target intervals, the pattern reverses (see especially Schlaghecken \& Eimer, 2004).

\section{Prime Validity Effects in the Arrow Classification Task}

Recent research by Klapp (2007) has demonstrated a prime validity effect using masked primes in an arrow classification task. Specifically, Klapp (2007) varied the proportion of incongruent prime-target pairs between subjects from $20 \%$ to $50 \%$ to $80 \%$, using both a relatively long, 160-msec prime-target interval (Experiment 2) and a short, 32-msec prime-target interval (Experiment 3). When the long prime-target interval was used, negative priming occurred, which increased in magnitude as the proportion of incongruent prime-target pairs increased. When the short prime-target interval was used, positive priming occurred, which increased in magnitude as the proportion of congruent prime-target pairs increased.

Focusing solely on the positive priming effect, Bodner and Mulji (in press) recently extended Klapp's (2007) research by showing that the proportion of congruent prime-target pairs for the arrow targets also affects response selection for either-way targets. Specifically, they interspersed free choice trials with arrow target trials and manipulated the proportion of congruent prime-target arrow classification trials between subjects, such that half of the participants received $80 \%$ congruent trials $(80 / 20$ condition) and the other half received $20 \%$ congruent trials $(20 / 80$ condition). Using a prime-target interval of $105 \mathrm{msec}$, they obtained a larger priming effect for the target arrow classification trials in the $80 / 20$ condition $(28 \mathrm{msec})$ than for those in the $20 / 80$ condition $(8 \mathrm{msec})$, which replicated Klapp's (2007) prime validity effect. Furthermore, the proportion of congruent prime-target pairs in the arrow classification trials also influenced response selection on the free choice trials. Responses were faster in the $80 / 20$ condition when the response corresponded with the direction of the masked prime (a 21-msec priming effect), but not in the $20 / 80$ condition (a nonsignificant 2-msec priming effect), and a response bias emerged, such that responses corresponded with the direction of the masked prime on $54.1 \%$ of the trials in the $80 / 20$ condition, but response selection was at chance (i.e., $49.1 \%$ ) in the $20 / 80$ condition.

Bodner and Mulji (in press) proposed that prime validity effects on both the arrow classification and free choice trials fit particularly well with their memory recruitment account. Specifically, priming effects occurred in the 80/20 condition, but were essentially nonexistent in the $20 / 80$ condition, because the participants in the $80 / 20$ condition often relied on episodic traces obtained from prime processing to aid target processing. In the 20/80 condition, however, the 
proportion of congruent trials was too low to be useful, so the participants placed virtually no reliance on the obtained episodic traces produced by prime processing.

\section{The Present Study}

What is important to note about Bodner and Mulji's (in press) account is the lack of a role for automatic response activation processes. That is, the only source of priming in their account is the use of episodic information about the prime in order to aid target processing. When the proportion of congruent prime-target trials is high (e.g., the $80 / 20$ condition), recruitment of prime information is frequent, and a positive priming effect emerges. In contrast, when the proportion is low (e.g., the 20/80 condition), virtually no recruitment of prime information takes place, and, consistent with Bodner and Mulji's results, no priming emerges. Where an account of this sort runs into problems, however, is in explaining negative priming effects (i.e., the fact that, with longer prime-target intervals, incongruent prime-target pairings tend to produce shorter latencies), since the recruitment of prime information can only aid processing. In order to explain inhibition effects, it would appear that Bodner and Mulji's account would have to assume that there is some role for response activation/inhibition processes. If their account were to do so, however, the question would then become why activation processes would not also play a role on positive priming trials (e.g., when the prime-target interval in the arrow classification task is short).

The present study is an attempt to evaluate the potential role of automatic response activation processes in the arrow classification task and the implications for Bodner and Mulji's (in press) account of their arrow classification data. To do so, the strongest possible manipulation of prime-target congruency in that task, combined with both a short (i.e., 77-msec) and a long (i.e., 165-msec) primetarget interval, was used, along with a set of either-way targets. Prime-target congruency for the arrow targets was manipulated between subjects across three different conditions. In two of these conditions, the prime-target relationship for the arrow targets was either $100 \%$ congruent (i.e., the prime arrow always pointed in the same direction as the target arrow) or 100\% incongruent (i.e., the prime and target arrows always pointed in opposite directions). The other condition was an unpredictive baseline condition in which arrow targets were preceded equally often by congruent and incongruent masked primes.

The key question concerns how the prime validity manipulation for the arrow targets affects the masked prime's impact (for both the reaction time and the response bias) on the intermixed either-way targets, specifically focusing on the relationship between the pattern in the unpredictive condition versus those in the $100 \%$ congruent and $100 \%$ incongruent conditions. Since the prime is of no use in terms of predicting the target in the unpredictive condition, our working assumption is that participants would have no motivation to recruit prime information in this condition. Thus, any impact of the prime in the unpredictive condition would, presumably, be due to automatic processing of the sort measured by Klapp and Hinkley (2002) and
Schlaghecken and Eimer (2004). If performance in the unpredictive condition is equivalent to that in the $100 \%$ incongruent condition (i.e., an essentially null priming effect), in support of Bodner and Mulji's (in press) claims, the implication would be that priming in the $100 \%$ congruent condition was due to the recruitment of prime information to aid target processing, with automatic activation processes playing little, if any, role. In contrast, if performance in the unpredictive condition is equivalent to that in the $100 \%$ congruent condition, the implication would be that the priming in the $100 \%$ congruent condition is essentially due to automatic activation processes rather than to the recruitment of prime information to aid target processing. Furthermore, it would mean that performance in the $100 \%$ incongruent condition was affected by some sort of participant action (e.g., an attempt to suppress an automatic bias created by the prime). A final possibility is that the unpredictive condition would show priming midway between those in the $100 \%$ congruent and $100 \%$ incongruent conditions. If so, the implication would be that the primes may be used in both the $100 \%$ congruent and the $100 \%$ incongruent conditions to either enhance or diminish the automatic activation initially created by the primes.

\section{METHOD}

\section{Participants}

One hundred forty-seven University of Western Ontario psychology undergraduate students received either course credit or $\$ 10$ for their participation in these experiments (age range $=17-53$ years, median $=23.2$ years). All had either normal or corrected-to-normal vision and were proficient in English.

\section{Materials}

There were two types of targets in these experiments. One type was a double arrowhead that pointed toward either the left $(<<)$ or the right $(>>)$. The other type was an either-way target, which consisted of one arrow that pointed right and one arrow that pointed left $(<>)$. Primes were also double arrowhead stimuli that pointed either left $(<<)$ or right $(>>)$. Masks consisted of single arrowheads pointing to both the left and the right $(><><><><) .{ }^{1}$ All stimuli were presented in 14-pt. Courier New font.

There were 360 test stimuli presented in six blocks of 60 trials each. Within each block of trials, there were 20 left-pointing arrow targets, 20 right-pointing arrow targets, and 20 either-way targets. Twentyfour practice trials ( 8 either-way targets, 8 right-pointing arrow targets, and 8 left-pointing arrow targets) preceded the test trials. For the arrow practice trials, half of the prime-target pairs were congruent (i.e., the prime and target arrows pointed in the same direction), and the other half were incongruent (i.e., prime and target arrows pointed in opposite directions). For the either-way practice targets, half of the targets were preceded by a right-pointing arrow prime, and half of the targets were preceded by a left-pointing arrow prime.

In terms of the experimental trials, in the unpredictive condition, the prime-target pairs for half of the arrow targets were congruent, and the prime-target pairs for the other half of the arrow targets were incongruent. In the $100 \%$ congruent condition, the arrow targets were always preceded by a prime arrow that pointed in the same direction as the target, whereas in the $100 \%$ incongruent condition, the arrow targets were always preceded by a prime arrow that pointed in the direction opposite that of the target. As was noted previously, this prime-target congruency manipulation was a between-subjects manipulation. In all three conditions, the either-way targets were preceded equally often by either a right-pointing or a left-pointing arrow prime. 


\section{Equipment}

The experiment was run using DMDX experimental software, produced by Forster and Forster (2003). The stimuli were presented on a SyncMaster monitor (Model No. 753DF). The presentation was controlled by an IBM-clone Intel Pentium. The stimuli appeared as black characters on a white background. Responses to stimuli were made by pressing one of the two "Shift" keys on the keyboard.

\section{Procedure}

The participants were run individually. The participants sat approximately $18 \mathrm{in}$. in front of the computer screen and were told by the experimenter that they would have to respond to both arrow targets and either-way targets, which would be presented on the screen. For the arrow targets, they were instructed to respond by pressing a key in the direction in which the target arrow was pointing (either left or right). For the either-way targets, they were told to respond by pressing either the left or the right key, and it was emphasized that either response was appropriate. For the arrow targets, the participants were told to respond as quickly and as accurately as possible. For the either-way targets, the participants were told to respond as quickly as possible without concerning themselves about which response they were making.

Each participant first performed the 24 practice trials with the experimenter in the room. Following these practice trials and after answering any questions that the participants may have had, the experimenter left the room, and the participants then performed the experimental trials, which consisted of six blocks of 60 trials (there was an opportunity for a break at the end of each block).

Each trial began with the presentation of a 550-msec arrow mask (e.g., $><><><><$ ), which acted as a fixation cue. This forward arrow mask was then followed by a 44-msec prime double arrowhead (e.g., $<<$ ), which was backward masked by a 33-msec arrow mask. The backward mask was followed by a 99-msec target that was either a double arrowhead (i.e., $>>$ or $<<$ ) or an either-way stimulus (i.e., $<>$ ). The participants had a maximum of $2.5 \mathrm{sec}$ to respond to the target stimulus before the next trial began. The key manipulation was the length of the prime-target interval. For 51 participants (17 in each prime condition), the prime-target interval was $77 \mathrm{msec}$, whereas for 96 participants (32 in each prime condition), the prime-target interval was increased to $165 \mathrm{msec}$ by inserting an 88 -msec blank screen between the backward mask and the target. Data collection in the $77-\mathrm{msec}$ condition was completed prior to beginning data collection in the 165 -msec condition.

At the end of the experiment, the experimenter asked the participants whether they were aware of anything that might have appeared before the target stimulus.

\section{RESULTS}

None of the participants reported that they had noticed any of the primes on the screen prior to the targets. Therefore, one can assume that the participants possessed little or no conscious awareness of the existence of the primes. Prime discrimination tasks were also carried out with separate groups of participants, using the display parameters for both prime-target intervals. These data also indicate that the participants had little awareness of the primes at either prime-target interval (see the Appendix for a description of the prime discrimination task).

For the arrow targets, latency and error data in the unpredictive condition were analyzed using a 2 (primetarget congruity: congruent vs. incongruent) $\times 2$ (primetarget interval: short vs. long) mixed-design ANOVA, whereas latency and error contrasts between the $100 \%$ congruent and $100 \%$ incongruent conditions were ana- lyzed using a 2 (prime condition: $100 \%$ congruent vs. $100 \%$ incongruent) $\times 2$ (prime-target interval: short vs. long) between-subjects ANOVA. Latency responses to the either-way targets were analyzed using a 3 (prime condition: $100 \%$ congruent vs. unpredictive vs. $100 \%$ incongruent) $\times 2$ (response congruity: congruent vs. incongruent) $\times 2$ (prime-target interval: short vs. long) mixed-design ANOVA. The response bias to the eitherway targets was analyzed using a 3 (prime condition: $100 \%$ congruent vs. unpredictive vs. $100 \%$ incongruent) $\times 2$ (prime-target interval: short vs. long) mixeddesign ANOVA.

The interactions for both arrow and either-way target data were further analyzed using post hoc comparisons (using Bonferroni adjustments for multiple comparisons). In addition, incorrect responses to the arrow targets were removed from the latency analyses, along with either-way and arrow target trials that were shorter than $150 \mathrm{msec}$ or in which no response was given $(9.8 \%$ of the arrow target trials, $4.2 \%$ of the either-way target trials).

\section{Arrow Targets}

Unpredictive condition. In the latency analysis, there was a significant main effect of prime-target congruity $\left[F(1,47)=19.67, M S_{\mathrm{e}}=257.21, p<.001\right]$. Responses were $15 \mathrm{msec}$ faster when the prime and target arrows pointed in the same direction $(312 \mathrm{msec})$ than when they pointed in opposite directions $(327 \mathrm{msec})$. There was no main effect of prime-target interval $[F(1,47)=$ 0.27 , n.s.]. More important, the interaction was significant $\left[F(1,47)=57.03, M S_{\mathrm{e}}=257.21, p<.001\right]$. When the prime-target interval was $77 \mathrm{msec}$, responses were $41 \mathrm{msec}$ faster when the prime and the target pointed in the same direction $(295 \mathrm{msec})$ than when they pointed in opposite directions $(336 \mathrm{msec})[t(16)=7.42, S E=$ $5.50, p<.001]$ (i.e., positive priming). However, when the prime-target interval was increased to $165 \mathrm{msec}$, responses were $11 \mathrm{msec}$ faster when the prime and the target pointed in opposite directions $(318 \mathrm{msec})$ than when they pointed in the same direction $(329 \mathrm{msec})[t(31)=2.65$, $S E=4.01, p<.02]$ (i.e., negative priming).

In the error analysis, there were significant main effects of prime-target congruity $\left[F(1,47)=21.85, M S_{\mathrm{e}}=\right.$ $0.005, p<.001]$ and prime-target interval $[F(1,47)=$ 9.30, $\left.M S_{\mathrm{e}}=0.009, p<.005\right]$. The error rate was greater when the prime and target arrows pointed in opposite directions $(12.7 \%)$ than when they pointed in the same direction (5.8\%), and the error rate was greater when the prime-target interval was $77 \mathrm{msec}(12.3 \%)$ than when it was $165 \mathrm{msec}(6.2 \%)$. More important, the interaction was significant $\left[F(1,47)=41.29, M S_{\mathrm{e}}=0.005, p<.001\right]$. When the prime-target interval was $77 \mathrm{msec}$, the error rate was significantly greater when the prime and target arrows pointed in opposite directions $(20.4 \%)$ than when they pointed in the same direction $(4.1 \%)[t(16)=6.79$, $S E=0.024, p<.001]$ (i.e., positive priming). However, when the prime-target interval was increased to $165 \mathrm{msec}$, the error rate was nonsignificantly greater when the prime and target arrows pointed in the same direction (7.4\%) 
Table 1

Results for Either-Way Responses (Reaction Times

in Milliseconds, Response Biases in Percentages)

\begin{tabular}{|c|c|c|c|c|c|}
\hline \multirow{3}{*}{$\begin{array}{l}\text { Prime-Target } \\
\text { Relationship }\end{array}$} & \multirow{2}{*}{\multicolumn{2}{|c|}{ Response Bias }} & \multicolumn{2}{|c|}{ Response Latency } & \multirow[b]{3}{*}{$P E$} \\
\hline & & & \multirow{2}{*}{$\begin{array}{l}\text { Opposite } \\
\text { Direction }\end{array}$} & \multirow{2}{*}{$\begin{array}{c}\text { Same } \\
\text { Direction }\end{array}$} & \\
\hline & Congruent & Incongruent & & & \\
\hline \multicolumn{6}{|c|}{ 77-msec Prime-Target Interval } \\
\hline Baseline & 57.6 & 42.4 & 372 & 334 & 38 \\
\hline Congruent & 60.8 & 39.2 & 366 & 333 & 33 \\
\hline Incongruent & 49.4 & 50.6 & 431 & 423 & 8 \\
\hline \multicolumn{6}{|c|}{ 165-msec Prime-Target Interval } \\
\hline Baseline & 47.2 & 52.8 & 378 & 384 & -6 \\
\hline Congruent & 49.5 & 50.5 & 386 & 386 & 0 \\
\hline Incongruent & 44.8 & 55.2 & 365 & 386 & -21 \\
\hline
\end{tabular}

Note-Response bias refers to the percentage of trials in which the response corresponded to the direction of the prime. Response latency refers to the speed of response with reference to the direction of the prime arrow.

than when they pointed in opposite directions $(4.9 \%)$ $[t(31)=1.53$, n.s. $]$ (i.e., negative priming).

$100 \%$ congruent versus $100 \%$ incongruent comparison. For the latency analysis, neither the main effect of prime-target interval $[F(1,94)=1.47$, n.s. $]$ nor the main effect of prime condition $[F(1,94)=2.35$, n.s. $]$ was significant. The interaction was significant $[F(1,94)=$ $\left.9.81, M S_{\mathrm{e}}=3,871.40, p<.003\right]$. When the prime-target interval was $77 \mathrm{msec}$, responses were $62 \mathrm{msec}$ faster when the prime and target arrows pointed in the same direction (i.e., the $100 \%$ congruent condition; $300 \mathrm{msec}$ ) than when they pointed in opposite directions (i.e., the $100 \%$ incongruent condition; $362 \mathrm{msec}$ ) $[t(32)=2.89, S E=$ $21.34, p<.006$ ] (i.e., positive priming). However, when the prime-target interval was increased to $165 \mathrm{msec}$, responses were a nonsignificant $21 \mathrm{msec}$ faster when the prime and target arrows pointed in opposite directions $(304 \mathrm{msec})$ than when they pointed in the same direction $(325 \mathrm{msec})[t(62)=1.36$, n.s.] (i.e., negative priming).

For the error analysis, neither the main effect of prime condition $[F(1,94)=0.16$, n.s.] nor the main effect of prime-target interval $[F(1,94)=0.01$, n.s. $]$ was significant. The interaction was also not significant $[F(1,94)=$ 0.46 , n.s.]. The error rates did not differ between the $100 \%$ congruent and $100 \%$ incongruent prime conditions for either the $77-\mathrm{msec}[t(32)=0.67$, n.s. $]$ or the $165-\mathrm{msec}$ $[t(62)=0.23$, n.s. $]$ prime-target interval $(5.4 \%$ vs. $6.3 \%$ and $5.7 \%$ vs. $5.1 \%$, respectively).

\section{Either-Way Targets}

Response latencies. There was a significant main effect of response congruity $\left[F(1,141)=7.21, M S_{\mathrm{e}}=\right.$ 743.87, $p<.009]$. Response latencies (see Table 1 ) were $9 \mathrm{msec}$ faster when the participants chose a response that corresponded with the direction of the prime $(374 \mathrm{msec})$ than when they chose a response that was in the direction opposite that of the prime $(383 \mathrm{msec})$. There was no main effect of prime-target interval $[F(1,141)=0.11$, n.s. $]$, but there was a marginal effect of prime condition $[F(2,141)=$ $\left.2.79, M S_{\mathrm{e}}=12,440.08, p<.07\right]$. Although only marginally significant, responses were longer in the $100 \%$ incongruent condition (401 msec) than in either the $100 \%$ congru- ent $(368 \mathrm{msec})[t(96)=2.02, p<.14]$ or the unpredictive condition $(367 \mathrm{msec})[t(96)=2.07, p<.13]$. The 1 -msec difference between the $100 \%$ congruent and unpredictive conditions was not significant $[t(96)=0.05$, n.s.]

All three two-way interactions were significant. To begin with, prime-target interval significantly interacted with response congruity $\left[F(1,141)=27.98, M S_{\mathrm{e}}=\right.$ $743.87, p<.001]$. When the prime-target interval was $77 \mathrm{msec}$, the participants' responses were $27 \mathrm{msec}$ faster when they corresponded with the direction of the prime $(363 \mathrm{msec})$ than when they differed $(390 \mathrm{msec})[t(50)=$ 4.93, $S E=5.40, p<.001$ ] (i.e., positive priming). When the prime-target interval was increased to $165 \mathrm{msec}$, however, responses were $9 \mathrm{msec}$ slower when they were in the same direction as the prime $(385 \mathrm{msec})$ than when they were in the opposite direction $(376 \mathrm{msec})[t(95)=2.21$, $S E=3.94, p<.03$ ] (i.e., negative priming).

Second, prime-target interval also interacted with prime condition $\left[F(2,141)=4.18, M S_{\mathrm{e}}=12,440.08\right.$, $p<.02]$. When the prime-target interval was $77 \mathrm{msec}$, responses in the $100 \%$ incongruent condition were slower than those in both the $100 \%$ congruent ( $427 \mathrm{vs.} 349 \mathrm{msec})$ $[t(47)=2.88, S E=27.05, p<.006]$ and the unpredictive $(427$ vs. $353 \mathrm{msec})[t(47)=2.74, S E=27.05, p<.008]$ conditions. There was no difference in response latencies between the $100 \%$ congruent and unpredictive conditions ( 349 vs. $353 \mathrm{msec}$ ) $[t(47)=0.14$, n.s.]. When the primetarget interval was increased to $165 \mathrm{msec}$, response latencies in the $100 \%$ incongruent condition did not differ from those in either the $100 \%$ congruent ( 376 vs. $386 \mathrm{msec}$ ) $[t(47)=0.52$, n.s. $]$ or the unpredictive $(376 \mathrm{vs.} 381 \mathrm{msec})$ $[t(47)=0.24$, n.s. $]$ condition, nor was there a significant difference between the $100 \%$ congruent and unpredictive conditions ( 386 vs. $381 \mathrm{msec})[t(47)=0.27$, n.s. $]$.

Finally, the interaction between prime condition and response congruity was also significant $[F(2,141)=$ 5.15, $\left.M S_{\mathrm{e}}=743.87, p<.008\right]$. Responses were faster when they corresponded to the direction of the prime than when they differed in both the $100 \%$ congruent (359 vs. $376 \mathrm{msec})[t(47)=2.90, p<.005]$ and the unpredictive (359 vs. $375 \mathrm{msec})[t(47)=2.82, p<.006]$ conditions. Responses in the $100 \%$ incongruent condition, however, 
were nonsignificantly slower when they corresponded to the direction of the prime than when they differed (405 vs. $398 \mathrm{msec})[t(47)=1.07$, n.s.]. The three-way interaction was not significant $[F(2,141)=0.48, \text { n.s. }]^{2}$

Response biases. There was a significant main effect of prime-target interval $\left[F(1,141)=67.09, M S_{\mathrm{e}}=\right.$ $0.004, p<.001]$. The bias to choose a response that corresponded with the direction of the prime was greater when the prime-target interval was $77 \mathrm{msec}(55.9 \%)$ than when it was $165 \mathrm{msec}(47.2 \%)$. There was also a significant main effect of prime condition $\left[F(2,141)=19.29, M S_{\mathrm{e}}=0.004\right.$, $p<.001]$. The participants were more likely to choose a response that corresponded with the direction of the prime in either the unpredictive $(52.4 \%)[t(47)=4.08, S E=$ $0.013, p<.001]$ or the $100 \%$ congruent $(55.1 \%)$ condition $[t(47)=6.15, S E=0.013, p<.001]$ than in the $100 \%$ incongruent condition $(47.1 \%)$. The difference in the response bias between the $100 \%$ congruent and unpredictive conditions was not significant $[t(47)=2.08$, n.s.]

In addition, the interaction of prime-target interval and prime condition was also significant $[F(2,141)=$ 3.73, $\left.M S_{\mathrm{e}}=0.004, p<.03\right]$. The participants were more likely to choose a response that corresponded with the direction of the prime when the prime-target interval was $77 \mathrm{msec}$ (as opposed to $165 \mathrm{msec}$ ) in all conditions - the $100 \%$ congruent condition $(60.8 \%$ vs. $49.5 \%)[t(47)=$ $5.95, S E=0.019, p<.001]$, the unpredictive condition $(57.6 \%$ vs. $47.2 \%)[t(47)=5.47, S E=0.019, p<$ $.001]$, and the $100 \%$ incongruent condition $(49.4 \%$ vs. $44.8 \%)[t(47)=2.47, S E=0.019, p<.02]$-with this contrast being slightly smaller in the $100 \%$ incongruent condition.

\section{DISCUSSION}

In the present study, we evaluated the mechanisms driving the prime validity effect in an arrow classification task with free choice trials when the arrow targets were preceded by masked primes that always pointed in the same direction as the target arrow (100\% congruent condition), always pointed in the opposite direction (100\% incongruent condition), or pointed equally often in the same and opposite directions (unpredictive condition) and when the prime-target interval was either 77 or $165 \mathrm{msec}$. Thus, in the present study, we employed both an unpredictive baseline condition and the strongest possible manipulation of prime-target congruency.

When the prime-target interval was $77 \mathrm{msec}$, the present study replicated Bodner and Mulji's (in press) pattern of prime validity effects for the either-way targets. That is, responses in the $100 \%$ congruent condition were $33 \mathrm{msec}$ faster when they corresponded with the direction of the prime ( $333 \mathrm{msec}$ ) than when they differed $(366 \mathrm{msec})$, but in the $100 \%$ incongruent condition, responses were only a nonsignificant $8 \mathrm{msec}$ faster when they corresponded with the direction of the prime $(423 \mathrm{msec})$ than when they differed $(431 \mathrm{msec})$. Similarly, the participants were more likely to choose a response that corresponded with the direction of the prime in the $100 \%$ congruent condition
(60.8\%) but were at chance performance in the $100 \%$ incongruent condition (49.5\%).

Critically for the present purposes, however, performance on the either-way targets in the unpredictive condition mimicked that in the $100 \%$ congruent condition. Specifically, responses to either-way targets in the unpredictive condition were $38 \mathrm{msec}$ faster when they corresponded with the direction of the prime $(334 \mathrm{msec})$ than when they differed $(372 \mathrm{msec})$, essentially equivalent to the 33-msec effect in the 100\% congruent condition, and there was a strong bias (57.6\%) to respond in the direction of the prime arrow, essentially equivalent to the $60.8 \%$ bias in the $100 \%$ congruent condition. Because the arrow targets in the baseline condition were preceded equally often by left and right pointing arrows and, hence, there would be no overall benefit to recruiting prime information, these results strongly suggest that the pattern in the $100 \%$ congruent condition is not the result of the participants' relying more heavily on information from the prime's episodic trace when the proportion of congruent trials was high (a key assumption of the memory recruitment account) but was, rather, due to automatic response activation.

A similar relationship among the three prime conditions emerged with the 165 -msec prime-target interval. Note, first of all, that the prime-target interval manipulation worked as predicted; that is, it turned positive priming effects into negative priming effects. For the arrow targets, when the prime-target interval was $77 \mathrm{msec}$, responses to the arrow targets were $62 \mathrm{msec}$ faster when the prime and target arrows pointed in the same direction (i.e., the $100 \%$ congruent condition) than when they pointed in opposite directions (i.e., the $100 \%$ incongruent condition), and, in the unpredictive condition, responses were $41 \mathrm{msec}$ faster when the prime and the target pointed in the same direction than when they pointed in opposite directions. With the 165 -msec prime-target interval, responses were $21 \mathrm{msec}$ faster in the $100 \%$ incongruent condition than in the $100 \%$ congruent condition, and responses in the unpredictive condition were $11 \mathrm{msec}$ faster when the prime and the target pointed in opposite directions than when they pointed in the same direction.

A similar pattern emerged with the either-way targets. In the $100 \%$ incongruent condition, the null bias shown in the 77-msec condition turned into a response bias in the direction opposite to that of the prime $(55.2 \%)$ in the $165-\mathrm{msec}$ condition, whereas the strong evidence for a bias in the direction of the prime disappeared in both the $100 \%$ congruent $(49.5 \%)$ and the unpredictive $(47.2 \%)$ conditions. Furthermore, in the $100 \%$ incongruent condition, the null priming effect with a 77-msec prime-target interval turned into a 21msec negative priming effect with a 165 -msec prime-target interval. At the same time, the significant priming effects in both the $100 \%$ congruent and the unpredictive conditions when the prime-target interval was $77 \mathrm{msec}$ disappeared. What these results indicate is that the prime-target interval manipulation altered the direction of the automatic bias created by the prime, as was expected on the basis of Eimer and colleagues' results (e.g., Eimer, 1999; Eimer \& Schlaghecken, 2002; Schlaghecken \& Eimer, 2000, 2002). 
Nonetheless, in spite of the complete reversal of the basic priming effect, the pattern among the three prime conditions did not change. Just as with the $77-\mathrm{msec}$ prime-target interval, the results obtained in the unpredictive condition using a 165 -msec prime-target interval mimicked those in the $100 \%$ congruent condition. Therefore, it would appear that, regardless of what prime-target interval was used, it was the processing operations taking place in the $100 \%$ incongruent condition that produced the observed prime validity effects.

\section{The Proposed Response Bias Suppression Account}

The explanation that we propose for how the $100 \%$ incongruent condition is responsible for producing a prime validity effect is that the participants in that condition actively worked to suppress the response bias that was rapidly and automatically activated by the prime. That is, in the $100 \%$ incongruent condition, the response that was automatically activated by the masked prime for the arrow target trials was always incorrect. Therefore, the participants acted to suppress this response bias by decreasing the activation of the primed response, which, in turn, allowed the competing response to become more active. The result is a null positive priming effect and no response bias with a short prime-target interval, and a negative priming effect and clear bias against the prime's direction with a longer prime-target interval. In contrast, the results in the $100 \%$ congruent and unpredictive conditions were driven by the automatic activation produced by the prime. Hence, following Eimer and colleagues' results (e.g., Eimer, 1999; Eimer \& Schlaghecken, 2002; Schlaghecken \& Eimer, $2000,2002)$, there was positive priming with the short prime-target interval and evidence of negative priming at the longer interval.

Note that this account is quite consistent with the fact that, with the 77-msec interval, responses were somewhat slower in the $100 \%$ incongruent condition $(427 \mathrm{msec}$ ) than in either the $100 \%$ congruent $(349 \mathrm{msec}$ ) or the unpredictive $(353 \mathrm{msec})$ condition - conditions that, once again, mimicked one another. When the prime-target interval was increased to $165 \mathrm{msec}$, however, there was no longer any difference among the three conditions: incongruent condition (376 msec), congruent condition (386 msec), baseline condition $(381 \mathrm{msec})$. These results, therefore, suggest that the participants had considerable difficulty responding in the incongruent condition when the primetarget interval was $77 \mathrm{msec}$, as would be expected if they were actively working to suppress an automatically activated bias. However, since a longer prime-target interval not only allows more time to suppress that bias but also typically automatically produces an activation pattern that reverses the direction of the initial bias (as was documented by Eimer \& Schlaghecken, 1998), the overall latency differences between the conditions disappeared.

There are a number of ways in which this suppression process might work (see, e.g., Tipper's [2001] review of various mechanisms of inhibition of response tendencies, and see also Houghton \& Tipper, 1994). The present data, however, do not allow a specification of which mecha- nisms might have been active here. Note also that, in many of the mechanisms discussed by Tipper, the suppression process is not a fully unconscious process (i.e., some conscious activity is being applied to aid the inhibition process). With respect to the present analysis, however, the argument is not being made that the inhibition process necessarily involves conscious activity or that the process requires conscious knowledge of the relationship between the automatic bias created by the prime and the subsequent direction of the arrow target. Rather, the argument is that, in an effort to facilitate responding, the suppression process may develop unconsciously in much the same way that the process of recruiting episodic trace information is presumed to develop in the memory recruitment account (i.e., without the participants necessarily becoming aware of what they are doing or why).

\section{The Fate of the Memory Recruitment Account}

One obvious question is how the memory recruitment account would need to be altered in order to allow it to explain the present data. One possibility is that one could assume that the relationship between the use of the prime to aid processing and the proportion of congruent trials is not straightforward. For example, one could argue that if the proportion of congruent trials is at least $50 \%$, the participants may always use information from the prime to aid target processing. As a result, performance in the unpredictive and $100 \%$ congruent conditions would be expected to be equivalent. ${ }^{3}$

An assumption of this sort would allow the account to explain the results in the 77-msec prime-target interval condition, but it would not allow the account to explain the negative priming in the 165 -msec prime-target interval condition. For the memory recruitment account to be able to explain negative priming, some sort of activation process would need to be added to the account. If that process allowed for activation of the response in the direction opposite that of the prime at longer prime-target intervals, the amended account could explain the change in the either-way target data from positive to zero priming in the $100 \%$ congruent and unpredictive conditions and the change from zero to negative priming in the $100 \%$ incongruent condition. However, as was previously noted, adding this assumption to Bodner and Mulji's (in press) account would raise the question of why the assumption is made that there is no automatic (positive) activation process when the prime-target interval is short.

\section{Alternative Accounts of Masked Priming in the Arrow Classification Task}

Variations in associative strength between the prime and its response. As was previously described, Klapp (2007) reported that the magnitude of priming for arrow targets increased as the proportion of incongruent prime-target pairs varied between subjects from $20 \%$ to $50 \%$ to $80 \%$ in an arrow classification task using masked arrow primes. According to Klapp (2007), a masked prime becomes associated with a particular response if both the masked prime and the target signal the same response. Prime validity effects, therefore, arise because of the fact 
that this association becomes stronger (which results in a more effective masked prime) when the proportion of compatible prime-target trials is high.

The key difficulty Klapp's (2007) account would have in explaining the present data is that his account would appear to predict that there should be a difference in the size of the priming effects for either-way targets between the $100 \%$ congruent and unpredictive conditions at both prime-target intervals. The nonsignificant differences between these conditions at both prime-target intervals suggest that it is not variations in associative strength between the prime stimulus and its response that drove the prime validity effects in the present study.

Note, however, that, although the magnitude of priming for either-way targets did not differ between the unpredictive and the $100 \%$ congruent conditions at either primetarget interval in the present study, the magnitude of priming for the arrow targets did differ between Klapp's (2007) $50 \%$ and $80 \%$ congruent conditions. Thus, Klapp's (2007) account is consistent with his own data. Furthermore, it is unclear what may have produced a discrepancy between Klapp's (2007) data and the present data. One could argue that the cognitive system reacts differently to primes when their associated responses are always either consistent or inconsistent with the target relative to when their response consistency varies across trials (see note 3 ). In essence, the argument would be that the $100 \%$ conditions do not represent the most extreme manipulation of relatedness proportion but, rather, represent a qualitative change from relatedness proportions less than $100 \%$. Whether this is the reason for the discrepancy remains a question for future research.

A two-component account of masked priming. Kinoshita and Hunt (2008) recently proposed a twocomponent account of masked priming/congruence effects in a categorization task. According to their account, there is an unconditional component that reflects priming driven by stimulus-response associations (with used primes that had been responded to as targets) and a conditional component that reflects the congruence between the prime and target in terms of task-defined features. Both of these components operate automatically. However, the unconditional component is assumed to be transitory, since it either decays rapidly or is actively suppressed, whereas the conditional component is assumed to be independent of response latency, since it is time-locked to the target.

Kinoshita and Hunt's (2008) account was derived by applying a latency distribution analysis to a magnitude classification task (i.e., is a target number larger/smaller than 5?) and has yet to be applied to the arrow classification task. However, one can assume that their account would predict that the observed priming effects in that task would be primarily driven by the unconditional component, because the arrow primes had been used as targets. According to their account, priming from this component either decays rapidly or is actively suppressed. Response decay alone could not explain the reversal to negative priming at the $165-\mathrm{msec}$ prime-target interval. However, an active suppression mechanism that operates along the lines of what we propose here could. That is, it would have to be a suppression mechanism that is sensitive to the nature of the prime-target relationship (allowing it to play a major role in the $100 \%$ incongruent condition), as well as being one that could produce an overall level of activation in the initially primed response that is lower than the resulting level of activation of the opposing response.

Adaptation to the statistics of the environment model. In the arrow classification task (with and without free choice trials), there are only two possible responses (i.e., left or right) and a small number of targets (i.e., left arrows, right arrows, and, potentially, two-sided arrows) that are repeated multiple times over the course of the experiment. The mechanism that is posited here to explain prime validity effects, a mechanism that is somewhat different from those proposed by the memory recruitment account, may also explain prime validity effects in other tasks in which stimulus-response mappings can be formed through multiple repetitions of a small set of targets over the course of the experiment. One task in which prime validity effects have occurred that fits this criterion is Bodner and Dypvik's (2005) masked parity judgment task. Whether the mechanism proposed here does, in fact, extend to the masked parity judgment task is currently being investigated.

On the other hand, it is unlikely that the mechanism proposed here can explain prime validity effects in tasks that have a large target set and rarely repeat the targets (e.g., lexical decision, naming). Tasks like these do not allow the development of response biases on the basis of specific stimulus-response mappings, which would then become stronger through practice. Thus, those types of tasks would appear to provide better support for the memory recruitment account. However, recent research by Kinoshita, Forster, and Mozer (2008) challenged the memory recruitment account of prime validity effects in Bodner and Masson's (2004) masked prime naming task, albeit on a different basis from that discussed here. Essentially, Kinoshita et al. argued that the mechanisms that produce prime validity effects in that paradigm are the same mechanisms that produce blocking effects in a naming task (see Lupker, Brown, \& Colombo, 1997; Taylor $\&$ Lupker, 2001). That is, these prime validity effects are due to the fact that the difficulty of items within a block of trials strongly influences naming latencies.

More specifically, in a masked prime naming task, targets preceded by a masked repetition prime would be easier to process than targets preceded by an unrelated prime. Therefore, when a block of trials contains a large proportion of masked repetition trials, there should be a noticeable reduction in response latency for those trials in comparison to when those trials appear in a block with mainly unrelated trials. Such is not necessarily the case for the unrelated trials, because participants have somewhat less ability to speed up responding on those (more difficult) trials (i.e., latencies on those trials may be essentially similar in the high- and low-proportion blocks). Thus, according to Kinoshita et al. (2008), prime validity effects could emerge in this task as a result of the difficulty of the other trials within the block rather than as a result of the participants' placing more reliance on the prime when 
there is a large proportion of masked repetition trials (as was argued by Bodner and Masson, 2004). The question of whether Kinoshita et al.'s analysis is actually a better explanation of the data from these types of tasks than is the memory recruitment account, nonetheless, remains a question for future research.

\section{Conclusions}

In the present research, the mechanisms that drive the prime validity effect in an arrow classification task with free choice trials were investigated. The results indicate that varying the validity of the masked arrow primes for the arrow targets produced prime validity effects for both the response speed and the bias for the intermixed eitherway trials. The use of an unpredictive baseline condition demonstrated that these prime validity effects appear to be mainly driven by the processing in the $100 \%$ incongruent condition. That is, the prime validity effects arise as a result of participants' automatically suppressing response biases created by the initial automatic activation of the prime when those biases are inconsistent with the majority of the target stimuli. Although this conclusion does not contradict the memory recruitment account in general, it does suggest that at least some of the data taken as support for the memory recruitment account might be explained just as readily by mechanisms more consistent with the prospective view of masked priming (see also Klapp, 2007).

\section{AUTHOR NOTE}

This research was supported by Natural Sciences and Engineering Research Council of Canada Grant A6333 to S.J.L. The experiments reported here form part of J.R.P.'s dissertation research project. The authors thank Tasha Williamson and Lindsay Chan for their help in the data collection process. The authors also acknowledge the helpful comments from all three reviewers - Glen Bodner, Stuart Klapp, and Sachiko Kinoshita — on previous versions of this article. Correspondence concerning this article should be addressed to J. R. Perry or S. J. Lupker, Department of Psychology, University of Western Ontario, London, Ontario, N6A 5C2 Canada (e-mail: jperry23@uwo.ca or lupker@uwo.ca).

\section{REFERENCES}

Bodner, G. E., \& DypviK, A. T. (2005). Masked priming of number judgments depends on prime validity and task. Memory \& Cognition, 33, 29-47.

Bodner, G. E., \& Masson, M. E. J. (2001). Prime validity affects masked repetition priming: Evidence for an episodic resource account of priming. Journal of Memory \& Language, 45, 616-647. doi:10.1006/jmla.2001.2791

Bodner, G. E., \& Masson, M. E. J. (2003). Beyond spreading activation: An influence of relatedness proportion on masked semantic priming. Psychonomic Bulletin \& Review, 10, 645-652.

Bodner, G. E., \& Masson, M. E. J. (2004). Beyond binary judgments: Prime validity modulates masked repetition priming in the naming task. Memory \& Cognition, 32, 1-11.

Bodner, G. E., Masson, M. E. J., \& Richard, N. T. (2006). Repetition proportion biases masked priming of lexical decisions. Memory \& Cognition, 34, 1298-1311.

Bodner, G. E., \& MulJi, R. (in press). Prime proportion affects masked priming of fixed and free-choice responses. Experimental Psychology.

Damian, M. F. (2001). Congruity effects evoked by subliminally presented primes: Automaticity rather than semantic processing. Journal of Experimental Psychology: Human Perception \& Performance, 27, 154-165. doi:10.1037/0096-1523.27.1.154
EIMER, M. (1999). Facilitatory and inhibitory effects of masked prime stimuli on motor activation and behavioral performance. Acta Psychologica, 101, 293-313. doi:10.1016/S0001-6918(99)00009-8

Eimer, M., \& SchlaghecKen, F. (1998). Effects of masked stimuli on motor activation: Behavioral and electrophysiological evidence. Journal of Experimental Psychology: Human Perception \& Performance, 24, 1737-1747. doi:10.1037/0096-1523.24.6.1737

Eimer, M., \& Schlaghecken, F. (2002). Links between conscious awareness and response inhibition: Evidence from masked priming. Psychonomic Bulletin \& Review, 9, 514-520.

Forster, K. I., \& DaVIS, C. (1984). Repetition priming and frequency attenuation in lexical access. Journal of Experimental Psychology: Learning, Memory, \& Cognition, 10, 680-698. doi:10.1037/0278 $-7393.10 .4 .680$

Forster, K. I., \& Forster, J. C. (2003). DMDX: A Windows display program with millisecond accuracy. Behavior Research Methods, Instruments, \& Computers, 35, 116-124.

Houghton, G., \& TipPeR, S. P. (1994). A model of inhibitory mechanisms in selective attention. In D. Dagenbach \& T. H. Carr (Eds.), Inhibitory processes in attention, memory, and language (pp. 53-112). San Diego: Academic Press.

JaśKowski, P., \& PrZeKoracka-KrawcZyK, A. (2005). On the role of mask structure in subliminal priming. Acta Neurobiologiae Experimentalis, 65, 409-417.

JaŚKOWski, P., Skalska, B., \& Verleger, R. (2003). How the self controls its "automatic pilot" when processing subliminal information. Journal of Cognitive Neuroscience, 15, 911-920. doi:10.1162/ 089892903322370825

Kiesel, A., Berner, M. P., \& Kunde, W. (2008). Negative congruency effects: A test of the inhibition account. Consciousness \& Cognition, 17, 1-21. doi:10.1016/j.concog.2006.11.003

Kinoshita, S., Forster, K. I., \& Mozer, M. C. (2008). Unconscious cognition isn't that smart: Modulation of masked repetition priming effect in the word naming task. Cognition, 107, 623-649. doi:10.1016/ j.cognition.2007.11.011

Kinoshita, S., \& HunT, L. (2008). RT distribution analysis of category congruence effects with masked primes. Memory \& Cognition, 36, 1324-1334. doi:10.3758/MC.36.7.1324

KLAPP, S. T. (2005). Two versions of the negative compatibility effect: Comment on Lleras and Enns (2004). Journal of Experimental Psychology: General, 134, 431-435. doi:10.1037/0096-3445.134.3.431

KLAPP, S. T. (2007). Nonconscious control mimics a purposeful strategy: Strength of Stroop-like interference is automatically modulated by proportion of compatible trials. Journal of Experimental Psychology: Human Perception \& Performance, 33, 1366-1376. doi:10.1037/0096 $-1523.33 .6 .1366$

KLAPP, S. T., \& HAAS, B. W. (2005). Nonconscious influence of masked stimuli on response selection is limited to concrete stimulus-response associations. Journal of Experimental Psychology: Human Perception \& Performance, 31, 193-209. doi:10.1037/0096-1523.31.1.193

KLAPP, S. T., \& Hinkley, L. B. (2002). The negative compatibility effect: Unconscious inhibition influences reaction time and response selection. Journal of Experimental Psychology: General, 131, 255269. doi:10.1037/0096-3445.131.2.255

Lleras, A., \& EnNS, J. T. (2004). Negative compatibility or object updating? A cautionary tale of mask-dependent priming. Journal of Experimental Psychology: General, 133, 475-493. doi:10.1037/0096 $-3445.133 .4 .475$

LlerAs, A., \& ENNS, J. T. (2005). Updating a cautionary tale of masked priming: Reply to Klapp (2005). Journal of Experimental Psychology: General, 134, 436-440. doi:10.1037/0096-3445.134.3.436

Lupker, S. J., Brown, P., \& Colombo, L. (1997). Strategic control in a naming task: Changing routes or changing deadlines? Journal of Experimental Psychology: Learning, Memory, \& Cognition, 23, 570590. doi:10.1037/0278-7393.23.3.570

Masson, M. E. J., \& Bodner, G. E. (2003). A retrospective view of masked priming: Toward a unified account of masked and long-term repetition priming. In S. Kinoshita \& S. J. Lupker (Eds.), Masked priming: The state of the art (pp. 57-94). New York: Psychology Press.

Schlaghecken, F., \& Eimer, M. (2000). A central-peripheral asymmetry in masked priming. Perception \& Psychophysics, 62, 1367-1382.

Schlaghecken, F., \& Eimer, M. (2002). Motor activation with and 
without inhibition: Evidence for a threshold mechanism in motor control. Perception \& Psychophysics, 64, 148-162.

SCHLAGHECKEN, F., \& EIMER, M. (2004). Masked prime stimuli can bias "free" choices between response alternatives. Psychonomic Bulletin \& Review, 11, 463-468.

Schlaghecken, F., \& Eimer, M. (2006). Active masks and active inhibition: A comment on Lleras and Enns (2004) and on Verleger, Jaśkowski, Aydemir, van der Lubbe, and Groen (2004). Journal of Experimental Psychology: General, 135, 484-494. doi:10.1037/0096 $-3445.135 .3 .484$

Schlaghecken, F., Klapp, S. T., \& Maylor, E. A. (2009). Either or neither, but not both: Locating the effects of masked primes. Proceedings of the Royal Society B, 276, 515-521.

SUMNER, P. (2008). Mask-induced priming and the negative compatibility effect. Experimental Psychology, 55, 133-141. doi:10.1027/1618 $-3169.55 .2 .133$

TAYLOR, T. E., \& LUPKER, S. J. (2001). Sequential effects in naming: A time-criterion account. Journal of Experimental Psychology: Learning, Memory, \& Cognition, 27, 117-138. doi:10.1037/0278 $-7393.27 .1 .117$

TIPPER, S. P. (2001). Does negative priming reflect inhibitory mechanisms? A review and integration of conflicting views. Quarterly Journal of Experimental Psychology, 54A, 321-343. doi:10.1080/ 02724980042000183

Verleger, R., JaśKowski, P., Aydemir, A., van der Lubbe, R. H. J., \& Groen, M. (2004). Qualitative differences between conscious and nonconscious processing? On inverse priming induced by masked arrows. Journal of Experimental Psychology: General, 133, 494-515. doi:10.1037/0096-3445.133.4.494

\section{NOTES}

1. There has been an active debate in recent years concerning the importance of the features of the mask in producing negative priming effects at longer prime-target intervals (see Jaśkowski \& PrzekorackaKrawczyk, 2005; Kiesel, Berner, \& Kunde, 2008; Klapp, 2005; Lleras \& Enns, 2004, 2005; Schlaghecken \& Eimer, 2006; Sumner, 2008; Verleger, Jaśkowski, Aydemir, van der Lubbe, \& Groen, 2004). Our goal in the present study was not to enter into that debate but, rather, to create a situation in which the direction of the priming effect would change from positive to negative as the prime-target interval increases while ensuring that the masked primes are subliminal (i.e., prime visibility is minimized). As was demonstrated by Klapp (2005), Schlaghecken and Eimer (2006), and Sumner (2008), it is clearly possible to obtain negative priming effects using masks that do not share features with the primes and targets, indicating that negative priming effects are not due to using masks with features. As was demonstrated by Lleras and Enns (2004), however, these types of masks both maximize the chances of observing negative priming and more effectively decrease prime visibility. Therefore, we chose to use a mask that shares features with the primes and targets.

2. To determine whether the congruity effects in the latency data on the arrow and either-way target trials share a common origin, the correlation between congruity effect sizes was calculated for the participants in the unpredictive conditions. A marginally significant correlation $[r(17)=.45, p<.07]$ when the prime-target interval was $77 \mathrm{msec}$ and a significant correlation $[r(32)=.52, p<.003]$ when the prime-target interval was $165 \mathrm{msec}$ suggest that these priming effects do, in fact, share a common origin.

3. We thank Glen Bodner for offering this suggestion.

\section{Experiments A1 and A2: Prime Discrimination}

\section{Method}

Although no participants in the main experiment of the present study reported noticing the primes, a prime discrimination task was administered to a separate group of participants to provide a further investigation of the question of prime visibility.

Participants. Twenty-two participants (age range $=17-35$ years, $M=19.45$ years) performed the task using a 77-msec prime-target interval, and 22 participants (age range $=17-20$ years, $M=18.36$ years) performed the task using a 165 -msec prime-target interval.

Procedure. Each participant performed 18 practice trials followed by 120 experimental trials (four blocks of 30 trials each). Each trial, both practice and experimental, began with a 550-msec arrow mask (e.g., $><><><<$ ) followed by a double arrowhead prime (e.g., $<<$ or $>>$ ), which was backward masked by a 33-msec arrow mask. A 99-msec stimulus (i.e., $><$ ) either directly followed the backward mask (Experiment A1) or followed the backward mask after an 88-msec blank interval (Experiment A2). For half of the trials, the prime pointed to the left, and for the other half of the trials, the prime pointed to the right. The participants had a maximum of $2.5 \mathrm{sec}$ to respond, to indicate the direction of the masked prime before the next trial began.

During the practice trials, the duration of the prime presentation decreased from $165 \mathrm{msec}$ (Trials 1-6) to $110 \mathrm{msec}$ (Trials 7-12) to $55 \mathrm{msec}$ (Trials 13-18). During the experimental trials, the prime was always presented for $44 \mathrm{msec}$. The participants were instructed to make a response even if they were not sure which direction the prime pointed or even whether there was a prime.

\section{Results}

To assess prime discriminability, a sensitivity measure $\left(d^{\prime}\right)$ was calculated. A hit was defined as correctly indicating that a left-pointing arrow prime pointed to the left, and a false alarm was defined as incorrectly indicating that a right-pointing arrow prime pointed to the left. In Experiment A1, the hit rate was $47.4 \%$ and the false alarm rate was $47.6 \%$. The resulting $d^{\prime}$ score of -.001 did not deviate from zero $[t(21)=0.02$, n.s.]. In Experiment A2, the hit rate was $52.9 \%$ and the false alarm rate was $51.5 \%$. The resulting $d^{\prime}$ score of .072 also did not deviate from zero $[t(21)=0.26$, n.s. $]$.

In summary, the prime discrimination results using the parameter settings for both prime-target intervals provide further evidence that, under the experimental display settings used here, the participants experienced little, if any, awareness of the prime. 